07,12

\title{
Образование нанометровых трещин и фрактолюминесценция при разрушении углеродной керамики
}

\author{
(ㄷ В.И. Веттегрень, А.Г. Кадомцев, И.П. Щербаков, Р.И. Мамалимов, В.Б. Кулик \\ Физико-технический институт им. А.Ф. Иофрфе РАН, \\ Санкт-Петербург, Россия \\ E-mail: Victor.Vettegren@mail.ioffe.ru
}

Поступила в Редакцию 7 июля 2020 г.

В окончательной редакции 7 июля 2020 г.

Принята к публикации 8 июля 2020 г.

Получен рамановский спектр поверхностного слоя толщиной $\approx 80 \mathrm{~nm}$ пористой углеродной керамики (пористость $\approx 5 \%)$. Анализ спектра показал, что керамика содержит кристаллы карбида кремния $6 H$-SiC и кремния. При разрушении керамики микрокристаллами алмаза возникала фрактолюминесценция (FL). Ее спектр содержал две полосы 1.6 и $1.9 \mathrm{eV}$. Первая образуется при разрушении кристаллов кремния, а вторая - кристаллов $6 H$-SiC. Получена временная зависимость интенсивности сигналов FL c временным разрешением 2 ns. Наблюдали три вида сигналов: один образуются при разрушении кристаллов $6 H$-SiC, второй - при разрушении кристаллов кремния, а третий при одновременном разрушении этих кристаллов. Появление сигналов связывается с образованием трещин, возникающих при прорыве барьеров, образующихся при пересечении плоскостей скольжения дислокаций в кристаллах карбида кремния и кремния. Оценен размер трещин в $6 H-\mathrm{SiC}-$ наименьший $-5.5 \mathrm{~nm}$, а наибольший $-\approx 18 \mathrm{~nm}$.

Ключевые слова: карбид кремния, кремний, фрактолюминесценция, разрушение, трещины.

DOI: $10.21883 /$ FTT.2020.11.50102.144

\section{1. Введение}

Исследования механизма разрушения кристаллов показали, что процесс их разрушения под влиянием механических напряжений начинается с накопления и объединения мельчайших зародышевых трещин [1-3]. Они образуются при прорыве цугами дислокаций барьеров, препятствующих их движению по плоскостям скольжения $[4,5]$.

Углеродная керамика при комнатной температуре обладает высокой хрупкостью, и существовали сомнения, справедлив ли этот механизм для нее? Однако за последние 20 лет появились работы, в которых были получены данные в его пользу. Так Zhang идр. [6] обнаружили на поверхности $6 H$-SiC базальные дислокации и частичные дислокации Франка после разрушения образцов керамики при комнатной температуре. Li идр, [7] нашли, что после наноиндентирования в поверхностном слое карбида кремния наблюдаются базальные и частичные дислокации Шокли, а в областях с высокой плотностью дислокаций - микротрещины. Yan и др. [8] обнаружили, что после наноиндентирования на поверхности $6 \mathrm{H}-\mathrm{SiC}$ появляются микротрещины.

Однако механизм образования трещин непосредственно во время действия механических напряжений до сих пор остался не исследованным. Основная трудность для наблюдения образования и роста мельчайших трещин - малость их размеров (меньше $1 \mu \mathrm{m}$ ). По этой причине процессы образования и роста трещин должен занимать несколько ns и ранее отсутствовали методы для наблюдения за трещинами в течение столь малых интервалов времени. Однако в последнее время в результате развития метода FL, оказалось возможным проследить за процессом разрушения кристаллов с временным разрешением 1-2ns [9-13]. Атомы на поверхности трещин, в первые несколько ns находятся в возбужденном состоянии, а затем переходят в основное состояние. Энергия возбуждения выделяется в виде сигналов FL. Анализ временной зависимости интенсивности этих сигналов, позволяет проследить за образованием и ростом мельчайших трещин.

В настоящей работе при помощи анализа сигналов FL изучена динамика образования и роста зародышевых трещин и при разрушении углеродной керамики.

\section{2. Объект и методы исследования}

Объектом исследований служила карбидокремниевая пористая керамика, изготовленная спеканием порошков $6 H$-SiC (размеры частиц - $\approx 0.2 \mu \mathrm{m})$ с добавками $\mathrm{Al}_{2} \mathrm{O}_{3}, \mathrm{Y}_{2} \mathrm{O}_{3}, \mathrm{~B}$ и $\mathrm{C}$ - несколько процентов (по весу). Температура спекания - от 1900 до $2200^{\circ} \mathrm{C}$. Пористость образцов — $\approx 5$ vol.\% [14].

Образцы представляли собой параллелепипеды с размерами $40 \times 2 \times 2 \mathrm{~cm}$. Их прижимали к круглой стальной пластине, на поверхности которой приклеены микрочастицы алмаза с размерами $\approx 7 \mu \mathrm{m}$. Пластина закреплена на оси электромотора. Скорость ее вращения $\approx 5 \mathrm{~m} / \mathrm{s}$.

Строение поверхности керамики исследовали при помощи рамановской спектроскопии. Рамановские спек- 

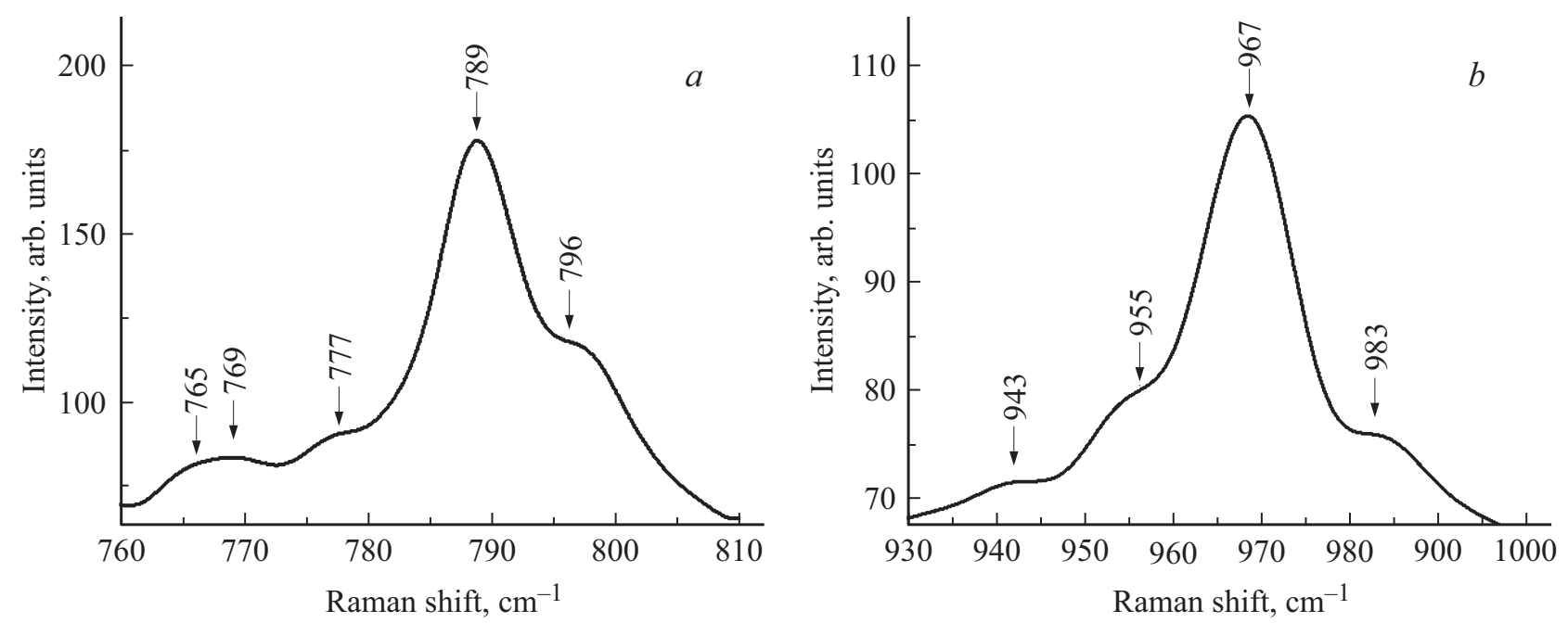

Pис. 1. Фрагменты рамановского спектра керамики в областях $760-810$ и 930-1000 $\mathrm{cm}^{-1}$.

тры возбуждали аргоновым лазером $\mathrm{Ar}^{2+} 16508$, длина волны излучения лазера $-488 \mathrm{~nm}$. Луч лазера фокусировался на поверхность образца. На ней он образовывал пятно диаметром $\approx 30 \mu$ m. Спектры записывали на спектрометре Ramalog 5. Угол рассеяния - $180^{\circ}$. Этот метод позволяет получить информацию о строении поверхностного слоя, эффективная толщина $h$ которого задана глубиной, на которой интенсивность поля электромагнитного излучения лазера затухает примерно в $e^{2} \approx 8$ раз. Значение $h$ вычислялось по формуле [10]: $h \approx \lambda / 4 \pi k$, где $\lambda$ - длина волны излучения лазера. Согласно J. Larruquert et. al [15], на длине волны лазера $\lambda=488 \mathrm{~nm}$ показатель поглощения $k=0.5$. Тогда $h \approx 80 \mathrm{~nm}$.

После включения электромотора возникала FL. Eе спектр зарегистрирован оптоволоконным спектрометром AvaSpec-ULSi2048L-USB2 OE.

Для исследования временной зависимости интенсивности сигналов FL излучение через кварцевую линзу фокусировали на поверхность фотоэлектронного умножителя ФЭУ-136. Электрическое напряжение на его выходе подавалось на вход аналогово-цифрового преобразователя ADC-3112 фирмы „АСТАСОМ“. Напряжение на выходе ADC через каждые 2 ns записывали в память компьютера.

\section{3. Строение поверхностного слоя керамики до разрушения}

На рис. 1 приведены два фрагмента рамановских спектров поверхностного слоя керамики. В них наблюдали полосы $765,769,789,796 \mathrm{~cm}^{-1}$ и $943,955,968 \mathrm{~cm}^{-1}$. Первые 4 полосы соответствуют поперечному (ТО), а вторые три - продольному оптическому (LO) фононам в $6 H$-SiC [16].

B спектрах некоторых областей поверхностного слоя керамики наблюдали полосу $625 \mathrm{~cm}^{-1}$ (рис. 2), со-

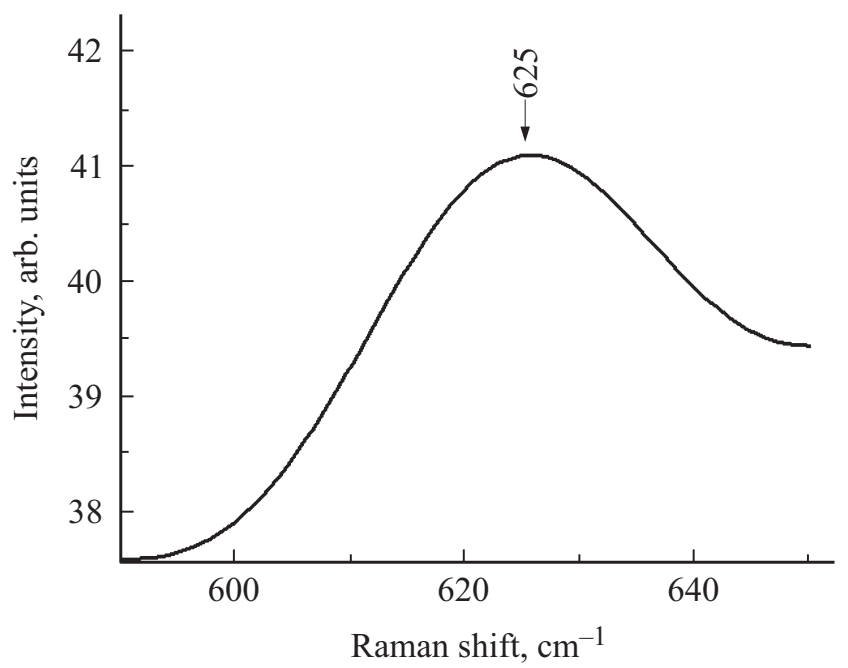

Рис. 2. Рамановский спектр, демонстрирующий существование кристаллов кремния в керамике.

ответствующую колебаниям кристаллической решетки кремния [17]. Это показывает, что в поверхностном слое керамики существуют области содержащие кристаллы кремния.

\section{4. Спектр FL керамики}

Спектр FL керамики показан на рис. 3. В нем наблюдается полоса с максимумом $\approx 1.88 \mathrm{eV}$. Она состоит из двух наложенных друг на друга полос $\approx 1.6$ и $\approx 1.9 \mathrm{eV}$, имеющих гауссову форму.

Полоса $1.6 \mathrm{eV}$ ранее наблюдалась при разрушении кристаллов кремния в работе Веттегреня и др. [13]. В работах Nakashima и Harima [16] и Russell [17], она приписана конфайнменту, т.е. увеличению ширины 


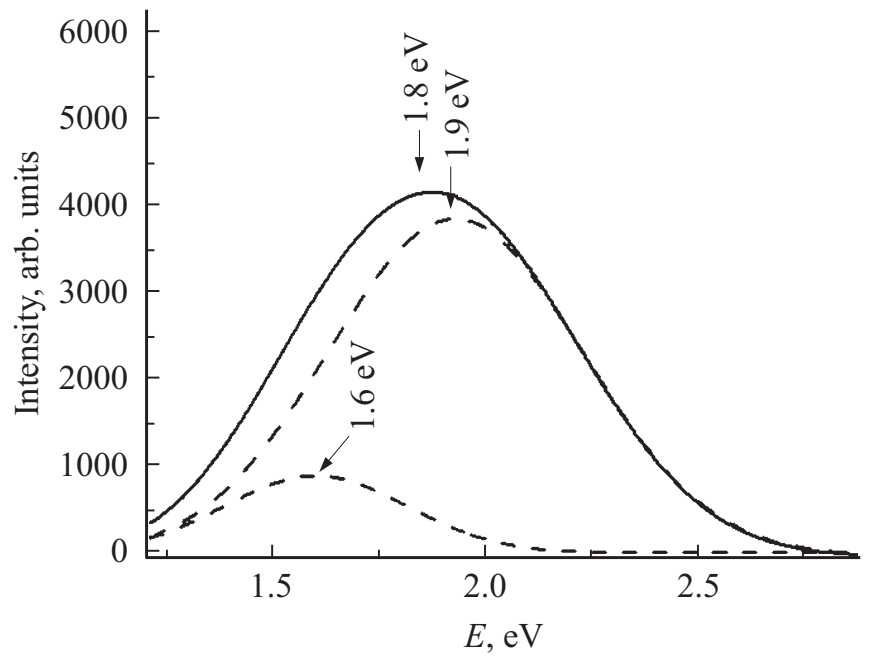

Рис. 3. Спектр FL при разрушении поверхностного слоя керамики.

запрещенной зоны и нарушению закона сохранения импульса в нанокристаллах кремния с размерами $\approx 4 \mathrm{~nm}$.

Weifang $\mathrm{Lu}$ и др. [18] наблюдали полосу $\approx 1.9 \mathrm{eV}$ в спектрах фотолюминесценции (PL) пористого $\mathrm{SiC}$. Авторы приписали ее рекомбинации донорно-акцепторных пар азота (донора) и бора (акцептора), связанного с $\mathrm{D}$-центрами в кристаллах $\mathrm{SiC}$. Однако в работах Лебедева с сотрудниками $[19,20]$ было показано, что в спектрах PL $p-n$-структур, легированных алюминием и азотом, такая полоса отсутствует.

Чтобы выяснить природу полосы, исследовали динамику сигналов FL при разрушении керамики.

\section{5. Динамика сигналов FL}

Временные зависимости сигналов FL представляют собой набор импульсов, интенсивность которых изменяется на порядок, а интервал времени между ними в среднем составлял $\approx 60 \mathrm{~ns}$ (рис. 4 ).

Наблюдали три вида сигналов.

Наиболее интенсивные сигналы (интенсивность в максимуме $\left.I_{m} \geq 600 \mu \mathrm{V}\right)$, как правило, состояли из трех, наложенных друг на друга максимумов (рис. 5). Первый максимум, обычно самый интенсивный, а два других имеют интенсивность приблизительно в два раза меньше. Длительность сигналов - $\approx 46-48 \mathrm{~ns}$, интервал между первым и вторым максимумами - $\approx 14 \mathrm{~ns}$, а между 2 и $3-\approx 20 \mathrm{~ns}$.

Наименее интенсивные сигналы $\left(I_{m} \leq 400 \mu \mathrm{V}\right)$ часто содержали 4 максимума (рис. 6). Длительность сигналов составляла $\approx 44-46 \mathrm{~ns}$, интервалы между 1,2 и 3 максимумами - (12-14)ns, а между 3 и 4 $(8-10)$ ns.

Наконец наблюдали сигналы, которые представляли собой результат наложения друг на друга сигналов обоих видов.
Каков же механизм возникновения такого вида сигналов FL? При механических воздействиях дислокации в кристаллах начинают двигаться по плоскостям скольжения. В местах пересечения таких плоскостей возникают барьеры, препятствующие движению дислокаций. Дислокации либо скапливаются и объединяются перед ним, либо, если напряжения достаточно велики, могут прорвать барьер. В обоих случаях, согласно Cottrell [4] и Владимирову [5], образуется трещина. В момент образования трещин атомы в кристаллических решетках переходят в возбужденное состояние [21]. При релаксации энергия возбуждения выделяется в виде излучения в видимой области спектра - FL. Во временной зависимости FL ей соответствует максимум.

Если кристаллическая решетка содержит несколько систем плоскостей скольжения, то число максимумов в каждом сигнале FL должно соответствовать числу таких систем. В работе Веттегреня с сотрудниками [13]

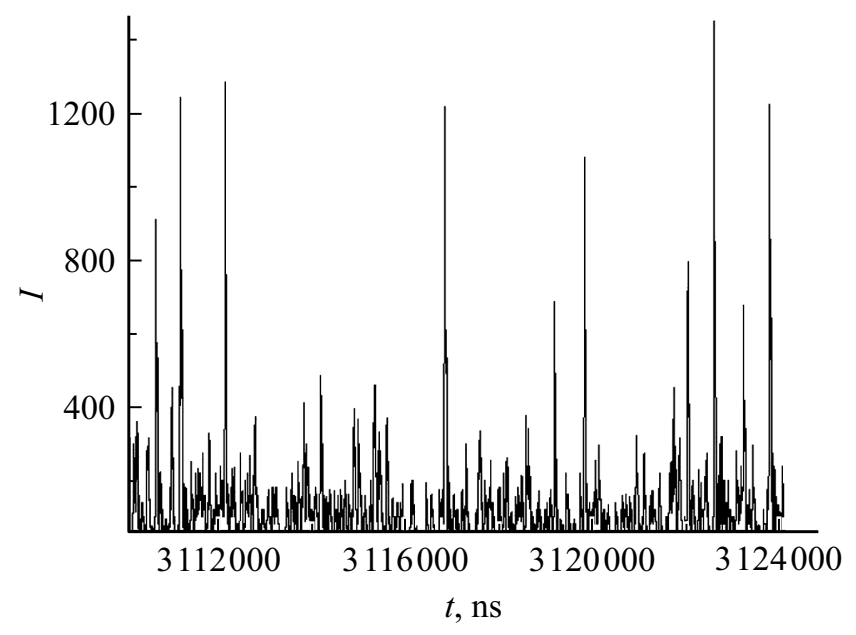

Рис. 4. Фрагмент временной зависимости интенсивности FL.

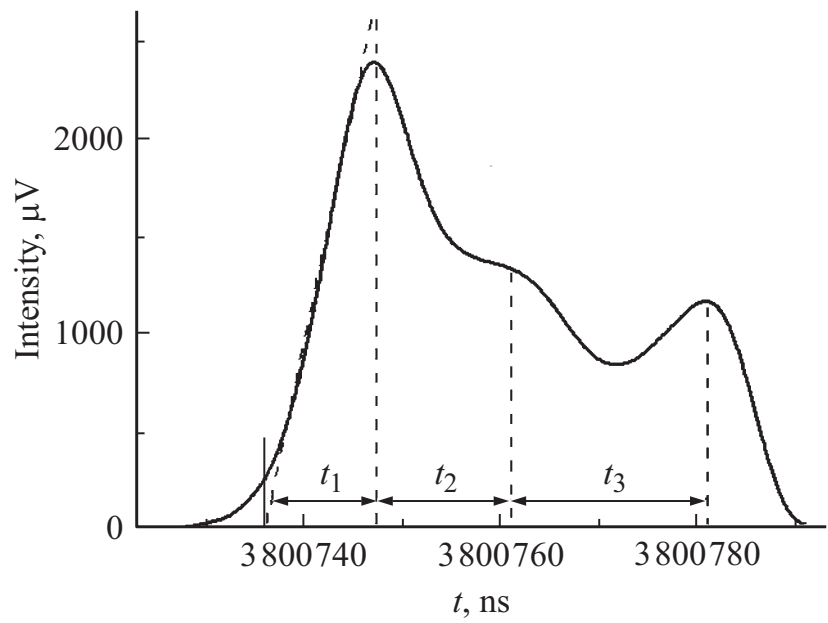

Рис. 5. Сигнал FL, соответствующий образованию трещин в карбиде кремния. $t_{1}, t_{2}, t_{3}-$ времена образования первой, второй и третьей трещин в кластерах. 
исследован вид сигналов FL при разрушении кристаллов кремния. Кристалл кремния обладает гранецентрированной кубической решеткой, и содержит 4 системы плоскостей скольжения дислокаций и, как и ожидалось, сигналы FL содержали по 4 максимума. Поэтому они были отнесены к трещинам, образующимся в нанокристаллах кремния при разрушении.

Как уже говорилось, наиболее интенсивные сигналы FL (рис. 5) содержат 3 максимума. Вероятно, они соответствуют трещинам, образующимся при прорыве барьеров в кристаллах $6 H$-SiC. Действительно, согласно Z. Li и др. [7], в кристаллической решетке $6 H$-SiC при комнатной температуре дислокации движутся по трем пересекающимся плоскостям скольжения. При разрушении барьеров, препятствующих их движению, должны образовываться кластеры из трех трещин. Во временной зависимости интенсивности FL таким кластерам соответствуют сигналы, содержащие 3 максимума (рис. 5). Полоса $1.9 \mathrm{eV}$ в спектре FL, по-видимому, соответствует появлению этих кластеров.

\section{6. Размеры и динамика трещин, образующихся при разрушении 6H-SiC}

Самая крупная из трещин образуется первой. Время ее образования - $t_{1} \approx 12 \mathrm{~ns}$ (рис. 5). Еще через $t_{2} \approx 14 \mathrm{~ns}$ образуется вторая, а затем через $t_{3} \approx 20 \mathrm{~ns}-$ третья. Размер площади берегов этих двух последних трещин в $\approx 2$ меньше, чем первой. По-видимому, после образования каждой трещины изменяются напряжения в ее окрестности, что создает благоприятные условия для образования следующей трещины, а величины $t_{2}$ и $t_{3}$ соответствуют временам перераспределения напряжений после образования первой и второй трещин.

На рис. 7 показано распределение интенсивности первого максимума - $I_{1}$ в сигналах FL. Она изменяется от $\approx 260$ до $\approx 2400 \mu \mathrm{V}$, т. е. приблизительно на порядок. Люминесцирующие центры располагаются на берегах трещин и интенсивность $I_{1}$ сигналов FL пропорциональна площади берегов трещин $S_{c}=Q I_{1}$. Поэтому линейный размер трещин $L=\sqrt{S}$ изменяется в $\approx 3$ раза.

Предположим, что скорость роста самых мелких из трещин, образующихся первыми, в кластерах приблизительно равна скорости деформации образца $-5 \mathrm{~m} / \mathrm{s}$. Как уже отмечалось, время их роста $t_{1}$ в сигналах $\mathrm{FL}=12 \mathrm{~ns}$. За это время площадь $S_{c}$ двух берегов первой трещины достигает величины $\approx 60 \mathrm{~nm}^{2}$, а ее линейный размер $L=\sqrt{S_{1} / 2} \approx 5.5 \mathrm{~nm}$. Размер второй и третьей трещины в кластерах в $\approx \sqrt{2} \approx 1.4$ раза меньше - $\approx 3.9 \mathrm{~nm}$ первой.

Первой трещине соответствует сигнал FL, интенсивность которого $I_{1}=2 S_{C} / Q=260 \mu \mathrm{V}$, где $Q=60 / 260$ $\approx 0.12 \mathrm{~nm}^{2} / \mu \mathrm{V}$. Трещин такого размера больше всего и излучение их поверхности вносит наибольший вклад в спектр FL.

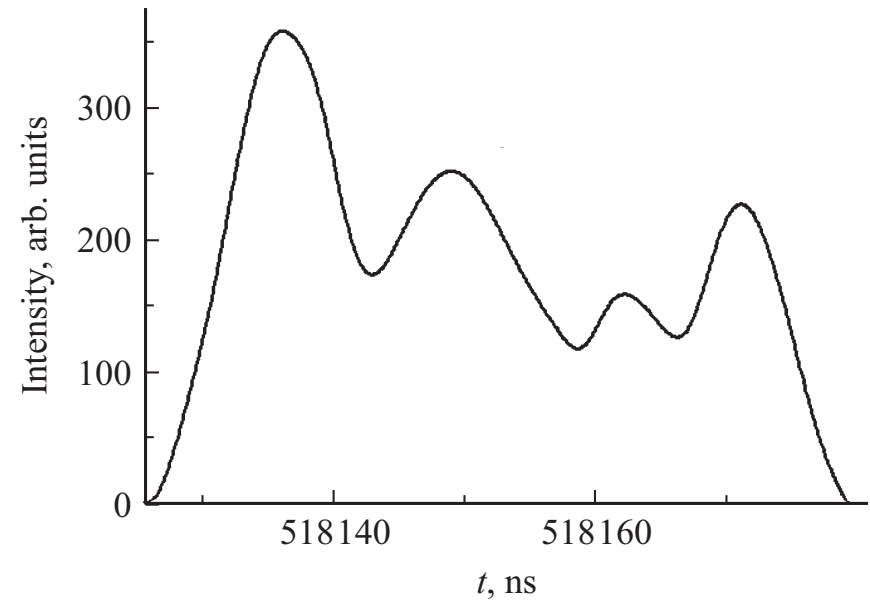

Рис. 6. Сигнал FL, возникающий при разрушении кристаллов кремния.

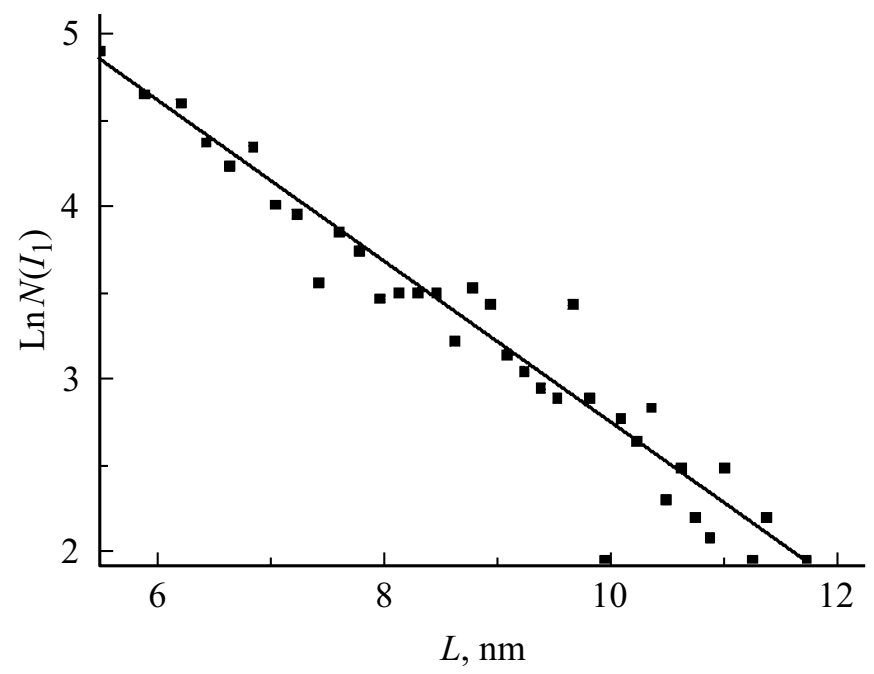

Рис. 7. Распределение размеров трещин в карбиде кремния.

Знание величины параметра $Q$ позволило вычислить размеры любых трещин $L_{C}$ по интенсивности первого максимума в сигналах FL, как $L_{C} \approx \sqrt{Q I_{C}}=\sqrt{0.12 I_{C}}$. Оказалось, что размеры трещин в углеродной керамике изменяются от 4.5 до $\approx 18 \mathrm{~nm}$. В кремнии их размер меньше - $\approx 4 \mathrm{~nm}[13]$.

На рис. 7 в полулогарифмических координатах показано распределение трещин по размерам. Видно, что число трещин уменьшается экспоненциально при увеличении их размера

$$
\operatorname{Ln} N=\operatorname{Ln} N_{0}-0.46 L_{C},
$$

где $N_{0}=134$ - число трещин с линейным размером $5.5 \mathrm{~nm}$. Такая зависимость показывает, что трещины образуются некоррелировано, т.е. независимо друг от друга. 


\section{7. Заключение}

При разрушении поверхностного слоя керамики образуются трещины, размеры которых варьируют от $\approx 4.5$ до $\approx 18 \mathrm{~nm}$. При образовании трещин возникают сигналы FL. Ее спектр содержит две полосы 1.6 и $1.9 \mathrm{eV}$. Первая соответствует излучению при образовании трещин в кристаллах кремния, а вторая - в кристаллах карбида кремния $6 H-\mathrm{SiC}$.

\section{Конфликт интересов}

Авторы заявляют, что у них нет конфликта интересов.

\section{Список литературы}

[1] В.Р. Регель, А.И. Слуцкер, Э.Е. Томашевский. Кинетическая природа прочности твердых тел. Наука, М. (1974). $560 \mathrm{c}$.

[2] В.И. Бетехтин, А.Г. Кадомцев. ФТТ 47, 5, 801 (2005).

[3] В.А. Петров, А.Я. Башкарев, В.И. Веттегрень. Физические основы прогнозирования долговечности конструкционных материалов. Политехника, СПб (1993). 475 с.

[4] A.H. Cottrell. Theory of Crystal Dislocations. Gordon and Breach, N.Y. (1964). $91 \mathrm{p}$.

[5] В.И. Владимиров. Физическая природа разрушения металлов. Металлургия, М. (1984). 280 с.

[6] B. Zhang, X.L. Zheng, H. Tokura, M. Yoshikawa. J. Mater. Proc. Technol. 132, 353 (2003)

[7] Z. Li, F. Zhang, X. Luo. Appl. Surf. Sci. 448, 341 (2018).

[8] J. Yan, X. Gai, H. Harada. J. Nanosci. Nanotech. 10 (2010).

[9] В.И. Веттегрень, А.В. Пономарев, К. Arora, Haris Raza, Р.И. Мамалимов, И.П. Щербаков, И.В. Фокин. ФТТ 60, 2266 (2018). DOI: 10.21883/FTT.2018.11.46674.057.

[10] M. Born, E. Wolf. Principles of optics. 2nd ed. Pergamon press, Oxford (1964). $856 \mathrm{p}$.

[11] В.И. Веттегрень, А.В. Пономарев, Р.И. Мамалимов, И.П. Щербаков. ФТТ 61, 1318 (2019). http://dx.doi.org/10.21883/FTT.2019.07.47844.413

[12] В.И. Веттегрень, А.В. Пономарев, Р.И. Мамалимов, И.П. Щербаков, К. Арора, Д. Шринагеш. Физика Земли 6, 76 (2019). http://dx.doi.org/10.31857/S0002-33372019676-83

[13] В.И. Веттегрень, Р.И. Мамалимов, И.П. Щербаков, В.Б. Кулик. ФТТ 62, 1070 (2020). DOI: 10.21883/FTT.2020.07.49475.041

[14] А.И. Слуцкер, А.Г. Кадомцев, В.И. Бетехтин, Е.Е. Дамаскинская, А.Б. Синани. Изв. РАН. Сер. физ. 73, 1496 (2009).

[15] J. Larruquert, A. P. Pérez-Marín, S. García-Cortés, L. Rodríguez-de Marcos, J.A. Aznárez, J.A. Méndez. J. Opt. Soc. Am. A. 28, 2340 (2011).

[16] S. Nakashima, H. Harima. Phys. Status Solidi 162, 39 (1997).

[17] J.P. Russell. Appl. Phys. Lett. 6, 11, 223 (1965). https://doi.org/10.1063/1.1754144

[18] Weifang Lu, Abebe T. Tarekegne, Yiyu Ou, Satoshi Kamiyama, Haiyan Ou. Sci. Rep. 9, 16333 (2019). https://doi.org/10.1038/s41598-019-52871-6
[19] А.А. Лебедев. ФТП 33, 2, 129 (1999).

[20] А.А. Лебедев. Н.К. Полетаев, М.Г. Растегаева, А.М. Стрельчук. ФТП 28, 1769 (1994).

[21] V.A. Zakrevsky, A.V. Shuldiner. Phil. Mag. B 71, 2, 127 (1995).

Редактор Д.В. Жуманов 